\title{
Association of physical activity, sedentary behaviours and sleep duration with cardiovascular diseases and lipid profiles: a Mendelian randomization analysis
}

Zhenhuang Zhuang ${ }^{1}$, Meng Gao ${ }^{1}$, Ruotong Yang ${ }^{1}$, Nan $\mathrm{Li}^{1,2}$, Zhonghua $\mathrm{Liu}^{3}$, Weihua Cao ${ }^{1 *}$ and Tao Huang ${ }^{1,4,5^{*}}$

\begin{abstract}
Background: Observational studies have shown that moderate-to-vigorous physical activity (MVPA), vigorous physical activity (VPA), sedentary behaviours, and sleep duration were associated with cardiovascular diseases (CVDs) and lipid levels. However, whether such observations reflect causality remain largely unknown. We aimed to investigate the causal associations of physical activity, sedentary behaviours, and sleep duration with coronary artery disease (CAD), myocardial infarction (MI), stroke and lipid levels.

Methods: We conducted a Mendelian randomization (MR) study using genetic variants as instruments which are associated with physical activity, sedentary behaviours, and sleep duration to examine the causal effects on CVDs and lipid levels. This study included analyses of 4 potentially modifiable factors and 7 outcomes. Thus, the threshold of statistical significance is $P=1.8 \times 10^{-3}(0.05 / 4 \times 7)$ after Bonferroni correction.

Results: In the present study, there was suggestive evidence for associations of genetically predicted VPA with CAD (odds ratio, $0.65 ; 95 \%$ confidence intervals, $0.47-0.90 ; P=0.009)$ and $\mathrm{MI}(0.74 ; 0.59-0.93 ; P=0.010)$. However, genetically predicted VPA, MVPA, sleep duration and sedentary behaviours did not show significant associations with stroke and any lipid levels.

Conclusions: Our findings from the MR approach provided suggestive evidence that vigorous exercise decreased risk of CAD and MI, but not stroke. However, there was no evidence to support causal associations of MVPA,sleep duration or sedentary behaviours with cardiovascular risk and lipid levels.

Translational perspective: The findings of this study did not point out specific recommendations on increasing physical activity required to deliver significant health benefits. Nevertheless, the findings allowed clinicians and public health practitioners to provide advice about increasing the total amount of excising time by demonstrating that such advice can be effective. Reliable assessment of the association of physical activity levels with different subtypes of CVDs is needed to provide the basis for a comprehensive clinical approach on CVDs prevention, which can be achieved through lifestyle interventions in addition to drug therapy.
\end{abstract}

Keywords: Physical activity, Cardiovascular diseases, Mendelian randomization, Causality

\footnotetext{
*Correspondence: caoweihua60@163.com; huangtaotao@pku.edu.cn

'Department of Epidemiology \& Biostatistics, School of Public Health, Peking University, 38 Xueyuan Road, Bejing 100191, China

Full list of author information is available at the end of the article
}

\section{$\triangle B M C$}

(c) The Author(s). 2020 Open Access This article is licensed under a Creative Commons Attribution 4.0 International License, which permits use, sharing, adaptation, distribution and reproduction in any medium or format, as long as you give appropriate credit to the original author(s) and the source, provide a link to the Creative Commons licence, and indicate if changes were made. The images or other third party material in this article are included in the article's Creative Commons licence, unless indicated otherwise in a credit line to the material. If material is not included in the article's Creative Commons licence and your intended use is not permitted by statutory regulation or exceeds the permitted use, you will need to obtain permission directly from the copyright holder. To view a copy of this licence, visit http://creativecommons.org/licenses/by/4.0/ The Creative Commons Public Domain Dedication waiver (http://creativecommons.org/publicdomain/zero/1.0/) applies to the data made available in this article, unless otherwise stated in a credit line to the data. 


\section{Background}

Cardiovascular diseases (CVDs) have become serious public health issues, which are the leading causes of death globally [1]. Etiology of CVDs is complex, including genetics and environmental factors such as diet and lifestyle [2-4]. A composite of light PA, sufficient sleep, and high sedentariness was responsible for the increased risk of CVDs according to a cross-sectional study [5]. Several observational studies have provided evidence for the significant association between CVDs and physical inactivity [6-8]. Importantly, a recent meta-analysis of 36 studies concluded that increased levels of physical activity was significantly associated with lower risk of CVDs [9]. Nevertheless, such observational studies were influenced by the possibility of confounding and reserve causation. In addition, epidemiological researches mainly rely on self-reported information, which may be inaccurate and subject to misclassification.

A recent community-based randomized controlled trial (RCT) suggested that physical activity had beneficial effects on adverse cardiovascular events in both the shortand medium-term [10]. Furthermore, there was a small benefit for reducing sedentary time to improve biomarkers of cardiometabolic risk in a cluster RCT [11]. Although RCTs have explored the effect of physical activity and sedentary behaviours on cardiovascular risk, the results are still inconclusive [10, 11]. Taken the limited duration of intervention trials into account, the information on potential long-term side effects may not be obtained, which also leads to bias in the results [12]. Therefore, the causal associations of physical activity, sedentary behaviours, and sleep duration with CVD remain uncertain.

The two-sample mendelian randomization (MR) is a widely used method for evaluating the casual relationships between risk factors and disease outcomes [13-16]. MR exploits the fact that alleles are randomly assigned from parents to offspring, which are unlikely to be affected by confounding factors. Moreover, issues of reverse causation are avoided because genotypes that are fixed at zygote formation could not be affected by diseases [17]. A recent MR study has shown that genetic instruments can be used to reveal causal relationships of physical activity with the risk of disease outcomes [18]. Therefore, such a method can be used in a large study design to uncover if and how lifestyle factors cause CVDs, under the premise that necessary assumptions are satisfied.

Therefore, in the present study, we used this MR approach to estimate the causal effect of physical activity, sedentary behaviours, and sleep duration on CVDs such as stroke, myocardial infarction (MI) and coronary artery disease (CAD). In complementary analysis, we investigated the role of four lifestyle factors on lipids including high density lipoprotein (HDL), low density lipoprotein (LDL), total cholesterol (TC) and triglycerides (TG).

\section{Methods}

\section{Exposure and instrumental variables}

We selected four lifestyle factors that have been shown to be strongly associated with CVDs in observational studies, including moderate-to-vigorous physical activity (MVPA), vigorous physical activity (VPA) [19-21], sedentary behaviours [22, 23], and sleep duration [24-26]. Then we searched PubMed and identified 3 publications reporting genome-wide association studies (GWAS) conducted for four lifestyle factors [27-29]. From these GWASs, 9 single nucleotide polymorphisms (SNPs) were identified with MVPA, 5 SNPs were identified with VPA, 4 SNPs were identified with sedentary behaviours and 7 SNPs were identified with sleep duration, showing strong association for genome-wide significance $(P<5 \times$ $\left.10^{-8}\right)$ with four lifestyle factors respectively. Besides, we chose the genetic variant with the lowest $P$ value for association with each lifestyle factor if genetic variants are in linkage disequilibrium (LD). We included summarized statistics (effect size estimates and their standard errors) on four lifestyle factors including MVPA, VPA, sedentary behaviours and sleep duration from published GWAS (Table 1). The SNPs significantly associated with the lifestyle factors in our study were used as instrumental variables (IVs) for lifestyle factors.

\section{Data sources}

For disease outcomes, the summary statistics are extracted from the Coronary ARtery DIsease Genome wide Replication and Meta-analysis (CARDIoGRAM) plus the Coronary Artery Disease (C4D) Genetics (CARDIoGRAMplusC4D) consortium for $\operatorname{CAD}(60,801$ cases and 123,504 controls), and MI (43,676 cases and 128,197 controls), respectively [30]; from the NINDS Stroke Genetics Network (SiGN) and International Stroke Genetics Consortium (ISGC) for stroke (37,792 cases and 397,209 controls) [31]. For lipid profiles, we extracted summary-level data from the Global Lipids Genetics Consortium (GLGC) consortium ( $n=188$, 577) for lipid levels such as HDL, LDL, TC and TG [32]. Detailed information about summary data for the associations of the genetic variants with the lifestyle factors and CVDs and lipid levels are presented in Table 2 and eTable 1-7.

CAD cases status were defined broadly, including MI, acute coronary syndrome, chronic stable angina, or coronary artery stenosis greater than 50\% [30]. Stroke cases were recruited between 1989 and 2012, aged 16 to 104 years, and subtypes of ischaemic stroke were recorded by centrally trained and certified investigators who used the web-based protocol, Causative Classification of Stroke (CCS) [31]. In addition, lipids GWAS evaluated the additive effects of each SNP on blood lipid levels after adjusting for age and sex, and individuals known to 


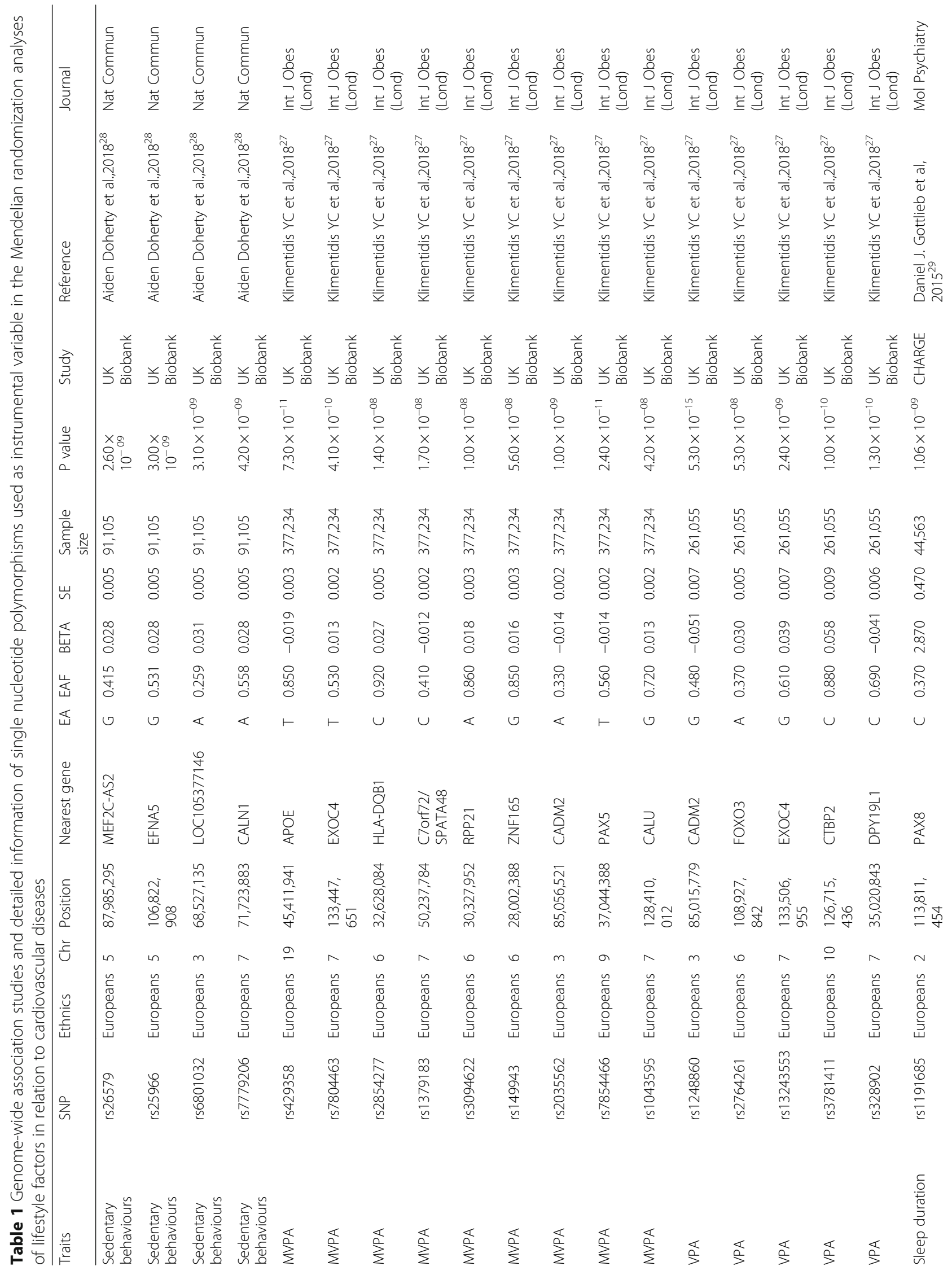




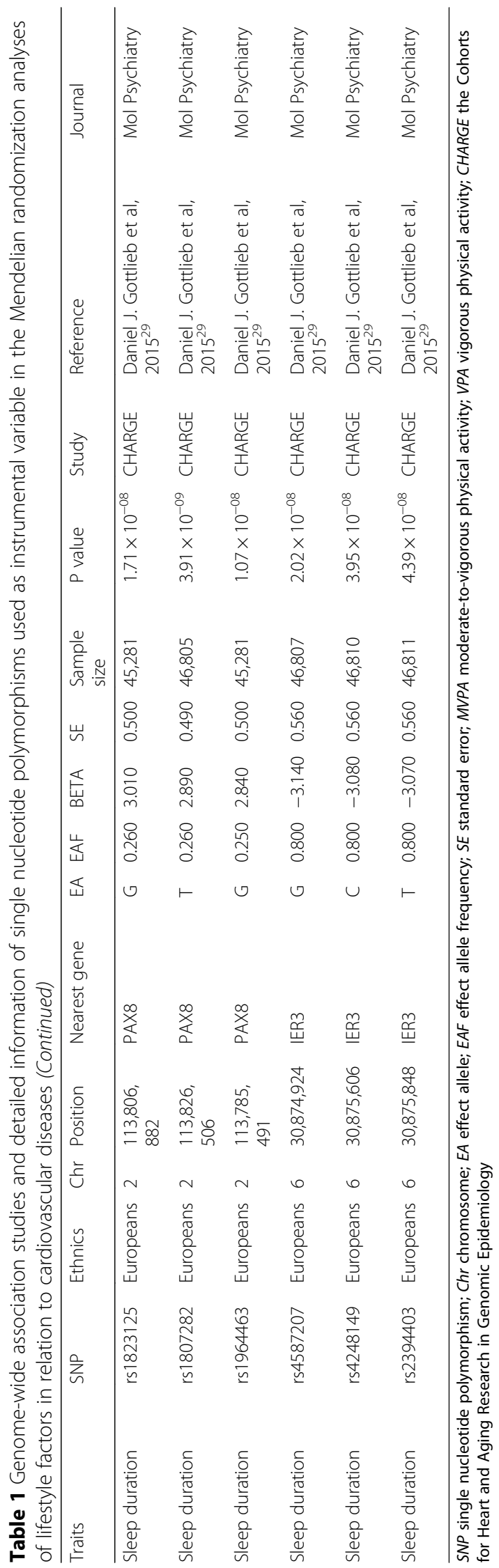


Table 2 Description of cardiovascular outcomes

\begin{tabular}{llll}
\hline Cardiometabolic factors & Consortium or study & Sample size & Population \\
\hline Lipids & The Global Lipids Genetics & 188,578 & Trans-Ethnics \\
Diseases & & & 2013 \\
CAD & CARDloGRAM and CARDloGRAMplusC4D & $60,801 / 123,504$ & Trans-Ethnics \\
MI & CARDloGRAM and CARDloGRAMplusC4D & $43,676 / 128,197$ & Trans-Ethnics \\
Stroke & SiGN and ISGC & $37,792 / 397,209$ & Trans-Ethnics \\
\hline
\end{tabular}

"Reports total sample size or case/controls;

Lipids include high density lipoprotein $(\mathrm{mg} / \mathrm{dL})$, low density lipoprotein $(\mathrm{mg} / \mathrm{dL})$, total cholesterol $(\mathrm{mg} / \mathrm{dL})$, triglycerides $(\mathrm{mg} / \mathrm{dL})$

CAD: coronary artery disease; MI: myocardial infarction; CARDloGRAMplusC4D: the Coronary ARtery Dlsease Genome wide Replication and Meta-analysis

(CARDIoGRAM) plus the Coronary Artery Disease (C4D) Genetics (CARDloGRAMplusC4D) consortium; SiGN: the NINDS Stroke Genetics Network; ISGC: International

Stroke Genetics Consortium

be on lipid levels lowering medications were excluded [32].

\section{Mendelian randomization analysis}

A two-sample MR method was used in the present study using summary level data with a beta-coefficient and the standard error from the regression of the lifestyle factors on the genotype and similar data for the regression of the disease outcomes on the genotype [12]. Recently, the twosample MR method is widely applied because of the large amount of public data from the global GWAS collaboration group. To make genetic variant qualified as a valid instrument for causal inference, the MR approach we used must satisfy the following three core assumptions: genetic variants are associated with the exposure; genetic variants are not associated with confounders; genetic variants influence risk of the outcome only through the exposure, not through other pathways (Fig. 1).

We first harmonized the effect of exposure and outcome data sets containing combined information on SNPs, phenotype, effect allele, effect size, standard error for selected SNPs. In the main analyses, we calculated the odds ratio (OR) and 95\% confidence intervals (CIs) for IVs by dividing the per-allele log-OR of CVDs by the per-allele difference in four lifestyle factors for each genetic variant respectively, using four different MR methods in which the conventional fixed effect inverse variance weighted method (IVW) is in a key position to get causal estimates. Besides, simple median method, weighted median method and MR-Egger regression method are performed as sensitivity analyses for lifestyle factors that are found to be significantly associated with CVDs. The weighted median method has a high

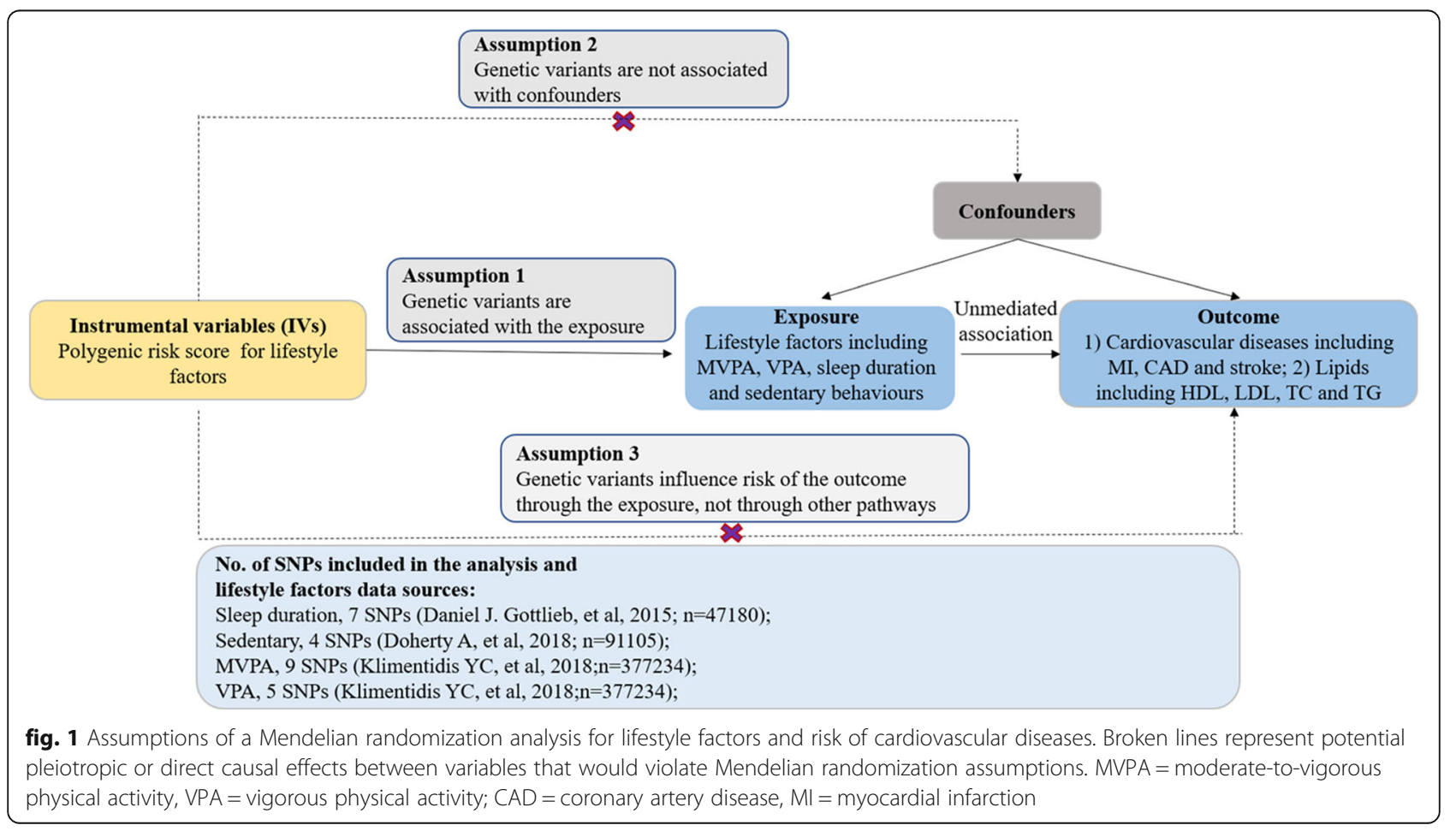


tolerance for pleiotropy, which provides a consistent estimate if at least $50 \%$ of the weight comes from valid SNPs. To see if there is directional pleiotropy existing in the IVW estimates, the MR-Egger analysis was conducted to test whether there is evidence of the intercept parameter being different from zero. In the absence of directional pleiotropy, the IV estimates of each SNP should be distributed symmetrically near the point estimation, indicating that there is no systematic bias in the results. Heterogeneity in odds ratio was quantified using the $\mathrm{I}^{2}$ test.

The results of the present study are shown as OR (95\% CIs) per genetically predicted increase in each lifestyle factor. We selected SNPs associated with self-reported levels of physical activity which were measured via a touchscreen questionnaire in the UK Biobank [27]. The measurement of MVPA like carrying light loads, cycling at normal pace was taking the sum of total minutes/ week of MVPA multiplied by four and the total number of VPA minutes/week multiplied by eight, which were corresponding to metabolic equivalents. However, minutes/week of VPA such as fast cycling, aerobics, heavy lifting were divided into those meeting the 3 days/week of VPA at 25/mins per day vs. 0 days of VPA because the heritability of VPA has previously been shown to be high [27]. Sedentary was measured by self-reported duration of sedentary behaviours, which may occur in sitting, reclining or lying postures [28]. Furthermore, sleep duration was measured by self-reported usual hours of sleep at night [29]. It's worth noting that the estimates represent the odds ratio per 1 unit higher log odds of the risk factor for the binary risk factors like VPA.

All analyses were performed with Stata version 14.2 (StataCorp, College Station, TX) and R version 3.5.3 (R foundation). Taken multiple testing into account, we applied Bonferroni correction in the genetic association analyses, thus the threshold of statistical significance is $0.05 /(3$ outcomes $\times 4$ factors $)=0.00417$. $P<0.05$ but above the Bonferroni corrected significance threshold was considered as suggestive evidence for a potential association.

\section{Results}

\section{Coronary artery disease (CAD)}

We found evidence of a potential protective effect of genetically predicted VPA on CAD (IVW OR, 0.65 for CAD per 1 unit higher log odds in VPA; 95\% CI, 0.47$0.90 ; P=0.009$ ) (Fig. 2 and eFigure 1); simple median and weighted median yielded similar pattern of effects; the results of the MR-Egger method confirmed the absence of evidence for directional pleiotropy $(P=0.258)$ (eTable 8). However, there was no significant association between CAD and genetically predicted MVPA (IVW OR, 1.38 for CAD per 1-SD higher in MVPA; 95\% CI, 0.55-3.47; $P=0.499$ ), genetically predicted sleep duration (IVW OR, 1.00 for CAD per 1-SD higher in sleep duration; $95 \% \mathrm{CI}, 0.99-1.00 ; P=0.162)$ or genetically predicted sedentary behaviours (IVW OR, 1.14 for CAD per 1-SD higher in sedentary behaviours; 95\% CI, 0.612.10; $P=0.687$ ), which provided insufficient data for alternative MR methods and sensitivity analyses (Fig. 2).

\section{Myocardial infarction (MI)}

Our MR results suggested higher log odds of genetically predicted VPA was associated with lower risk of MI (IVW OR, 0.74 for MI per 1 unit higher log odds in VPA; 95\% CI, 0.59-0.93; $P=0.010$ ) (Fig. 2 and eFig. 2);

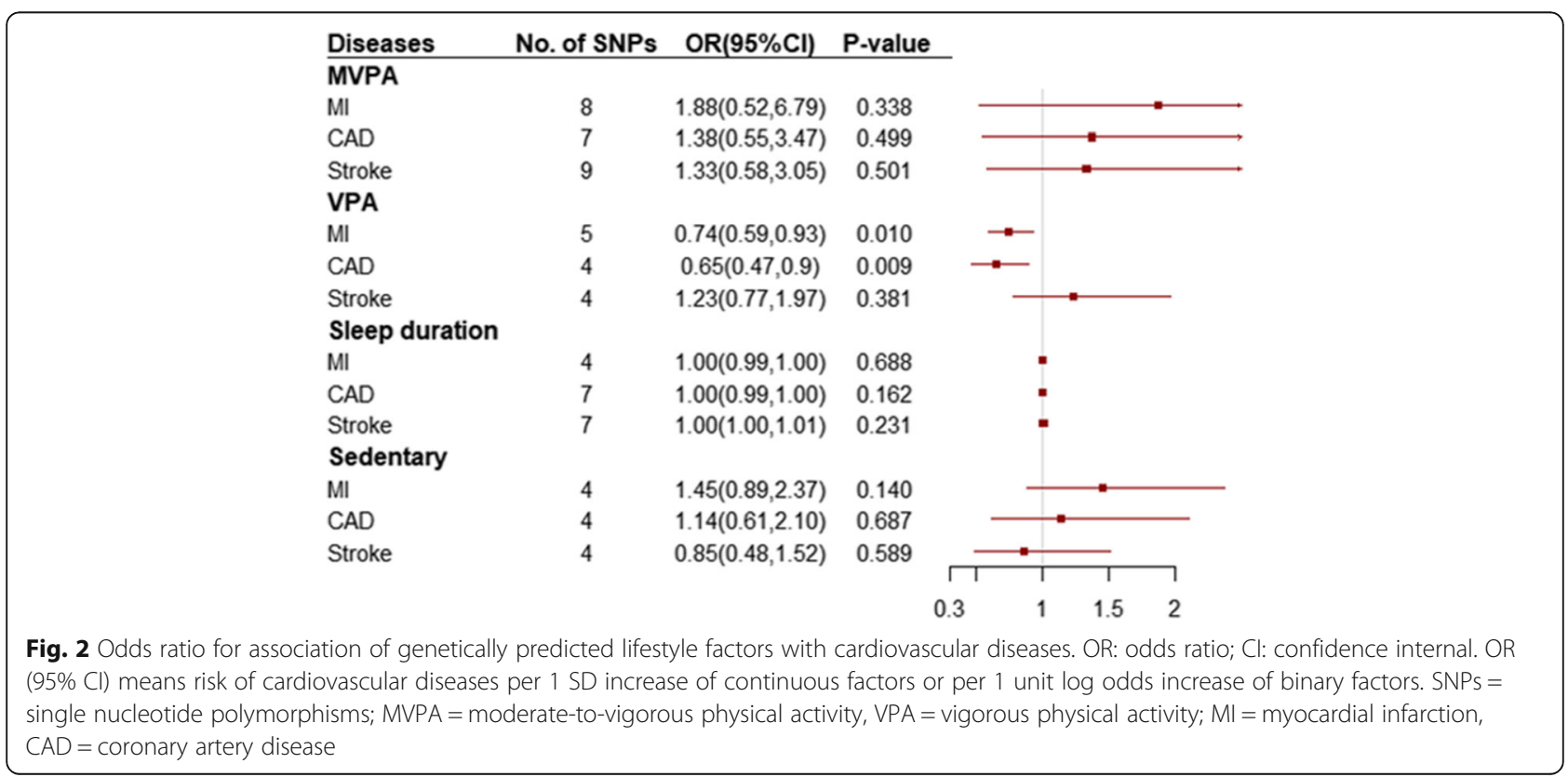


the simple median and the weighted median methods obtain consistent results with the IVW; there is no evidence of directional pleiotropy in the genetic instrument using the Egger intercept test $(P=0.560)$ (eTable 8). Nonetheless, we observed that genetically predicted MVPA (IVW OR, 1.88 for MI per 1-SD higher in MVPA; 95\% CI, 0.52-6.79; $P=0.338)$, genetically predicted sleep duration (IVW OR, 1.00 for MI per 1-SD higher in sleep duration; 95\% CI, 1.00-1.00; $P=0.688$ ), and genetically predicted sedentary behaviours (IVW OR, 1.45 for MI per 1-SD higher in sedentary behaviours; 95\% CI, 0.89-2.37; $P=0.140$ ) were not significant associated with MI (Fig. 2).

\section{Stroke}

There was no significant association to be found between four lifestyle factors and stroke, including genetically predicted MVPA (IVW OR, 1.33 for stroke per 1-SD higher in MVPA; 95\% CI, $0.58-3.05 ; P=0.501$ ), genetically predicted sleep duration (IVW OR, 1.00 for stroke per 1-SD higher in sleep duration; 95\% CI, 1.00-1.01; $P=0.231$ ), genetically predicted VPA (IVW OR, 1.23 for stroke per 1 unit higher log odds in VPA; 95\% CI, 0.77-1.97; $P=0.381$ and genetically predicted sedentary behaviours (IVW OR, 0.85 for stroke per 1-SD higher in sedentary behaviours; 95\% CI, 0.48-1.52; $P=0.589$ ) (Figure 2).

\section{Lipids}

We further examined the causal effects of the lifestyle factors on HDL, LDL, TC and TG, and we did not find that lifestyle factors SNPs were associated with any lipids (Fig. 3). Results were similar in sensitivity analyses that used the simple median and weighted median methods. However, directional pleiotropy existed in the associations of MVPA or sleep duration with almost all lipids $(\mathrm{P}<0.05)$, which may influence the results. (eTable 9).

\section{Discussion}

In the present study, using the MR approach, we for the first time investigated whether the previously observed significant associations of physical activity, sedentary behaviours and sleep duration with risk of CVDs were causal. The MR analysis supported the hypothesis that vigorous exercise may be an effective prevention strategy for CAD and MI. However, there was no evidence using this method and these SNPs to support the associations of MVPA, sedentary behaviours or sleep duration with cardiovascular outcomes and lipids.

Several observational studies have investigated the association of self-reported physical activity levels with incidence of CVDs. According to the PURE study, a prospective cohort study in 130000 people from 17 highincome, middle-income, and low-income countries, higher recreational and non-recreational physical activity was associated with a lower risk of mortality and CVD events [20]. A population-based prospective cohort study, which included 487,334 adults in 10 (5 urban, 5 rural) areas across China, suggested that total physical activity was inversely associated with the risk of major vascular events among Chinese adults [33]. A protective effect of physical activity on CVDs has also been observed in a smaller cohort study with median follow-up of 6.7 years [34]. Some epidemiology studies, mostly of RCTs, indicated that physical activity interventions was beneficial to improving

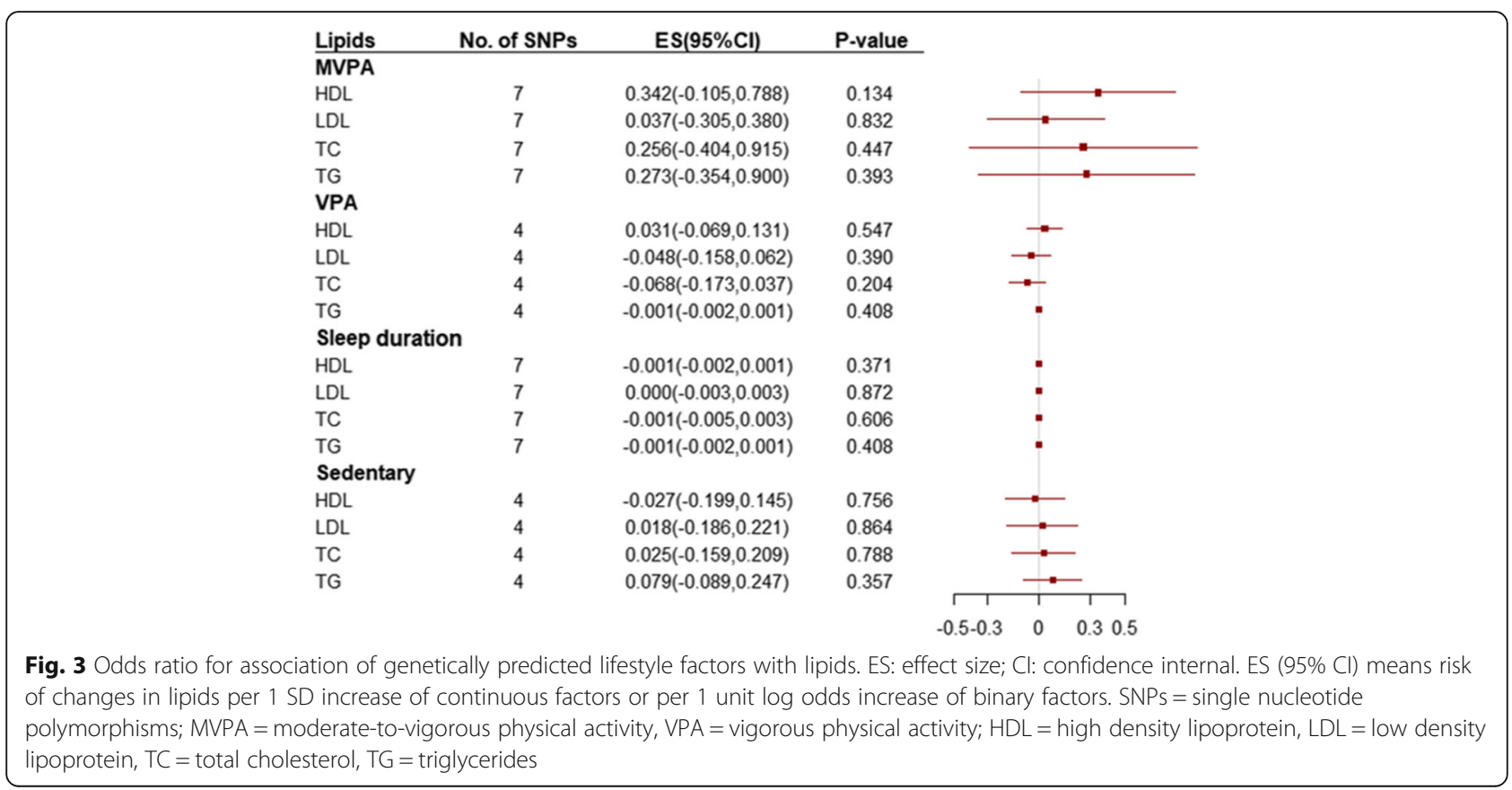


cardiovascular health $[10,35]$. To our best knowledge, the present study may be the first time to assess physical activity as a causal risk factor for CVDs including CAD, MI and stroke using the MR design with summarized data from GWAS with up to about 377,000 individuals [27]. The association appeared to be driven by VPA, whereas no association was observed with MVPA, which meant that vigorous activity levels seems to be more important than total activity time on high cardiovascular fitness [36].

We are not aware of any previous MR study assessing the association of generally predicted physical activity with CAD and MI. Our results of the potential relationship between physical activity and CAD or MI were consistent with a prospective population-based Rotterdam Study among 5901 elderly participants showing that specific physical activity types provided beneficial effects on risk of CAD [37]. Likewise, higher levels of leisure-time physical activity had a strong, graded, inverse association with the risk of acute myocardial infarction in a cohort study of 5-year follow-up [38]. In addition, a casecontrol study suggested that sports-related physical activity is associated with a lower risk of onset of AMI than inactivity in Chinese CAD patients [39].

Nevertheless, we found no significant association of physical activity with stroke, different from conclusions of previous observational studies that suggested physical activity reduced the risk of stroke $[40,41]$. But this MR study confirmed the findings from a Japanese prospective study showing that excessive vigorous-intensity activities might not be beneficial or even disadvantageous for prevention of hemorrhagic stroke for Japanese people [42]. Likewise, there was few significant effect of physical activity on lipid profiles among groups in intervention studies, which was consistent with our null finding [43, 44]. Further investigations are warranted to elucidate the potential association between physical activity and different stroke subtypes or lipids.

Furthermore, in the present MR analysis, there was no evidence of association of genetically predicted sleep duration, MVPA and sedentary behaviours with CVDs and lipids. Our results did not support previous finds from some observational studies, which showed that MVPA favorably reduced cardiometabolic risk [21] and sedentary behaviours and long sleep duration caused prejudice to cardiometabolic health [22-24] respectively. However, results from these epidemiology studies were inconsistent $[25,45,46]$. Our null findings suggested that the previously observational association between the lifestyle factors and cardiometabolic disease in earlier observational studies might be false positive which mainly attributed to reverse causation or confounding. The present analysis, using the genetic variants strongly associated with lifestyle factors explain a larger part of variance, shows the true null association. We cannot exclude, however, the possibility that such association may have been diluted because of the potential pleiotropy due to lots of variants. Therefore, further large intervention trial is needed to explore the effect of sleep duration, MVPA and sedentary behaviours on cardiovascular risk.

Accumulating evidence have suggested that regular physical activity has known health benefits and is associated with reduced risk of CVDs. According to previous study, VPA is defined as physical activities that make participants sweat or breathe hard such as fast cycling, aerobics and heavy lifting, without precise index measurements [27]. Increasing VPA can lower blood pressure, blood glucose and weight and improve lipid profile, which prevent primary and secondary cardiovascular events in both young and older adults [47]. However, the mechanistic pathways underlying the cardiovascular benefits of VPA are still not fully understood. One benefit of VPA is that the accumulated hemodynamic stimulation during aerobic exercise can induce antiatherosclerotic adaptation of vascular function and structure by releasing nitric oxide and myokines in ductal arteries that expand with movement, independent from other risk factors of CVDs [48]. Another interpretation is that VPA can also increase myocardial perfusion in the coronary collateralization, which not only improves blood flow to the heart but also protects against serious arrhythmias by cardiac autonomic balance improvement [48]. Increasing physical activity has been considered a simple, widely applicable, low cost global strategy that could reduce the risk of onset and deaths of CVDs. Recognizing the biological processes by which VPA affect the development of CVDs may help to understand the potential mechanisms.

Several strengths of this study merit consideration. First, we for the first time systematically assessed the causal effects of physical activity, sedentary behaviours and sleep duration in the development of CVDs using a MR approach. The MR analysis provided a better mean of generating a relatively less confounded estimates of causal relationships inferred without influenced by reverse causal effects or confounding. Second, in addition to traditional IVW method, we also adopted simple median method, weighted median method and MR-Egger method as sensitivity analysis to ensure the consistency of causal estimation, suggesting robustness of our findings. Third, besides this design technique, strengths of this study also included that summary statistics were collected from GWAS which included larger sample size than epidemiological studies, suggesting a higher statistical power for reliable causal estimation.

However, MR studies still have potential limitations although core assumptions have been met. First, genetic variants identified in GWAS often have small phenotypic 
effects, resulting in potentially weak instruments bias which depends on the strength of the genetic instruments through the F statistic. Second, population stratification is another limitation, which refers to the existence of the differences in allele frequencies and disease prevalence in different ethnic groups. Third, we assumed that the associations between lifestyle factors and CVDs are linear, which may not be consistent with the fact. Hence, the role of lifestyle factors including physical activity, sleep duration and sedentary behaviours in the development of CVDs needs further investigation. Finally, MR studies require large sample sizes to ensure enough power, which is not easy to calculate [49].

In conclusion, our study provided evidence to support the protective effect of vigorous exercise on CAD and MI, but not stroke, suggesting that aerobic exercise was a powerful approach for prevention of cardiovascular risk. However, larger intervention studies are needed to further explore the causal associations of physical activity, sedentary behaviours, and sleep duration with CVDs and lipid profiles.

\section{Supplementary information}

Supplementary information accompanies this paper at https://doi.org/10. 1186/s12944-020-01257-z

Additional file 1. Online supplemental materials.

\section{Abbreviations}

CVDs: Cardiovascular diseases; CAD: Coronary artery disease; Cls: Confidence intervals; GWAS: Genome-wide association studies; HDL: High density lipoprotein; IVW: Inverse variance weighted; LDL: Low density lipoprotein; MVPA: Moderate-to-vigorous physical activity; MI: Myocardial infarction; MR: Mendelian randomization; OR: Odds ratio; RCT: Randomized controlled trial; SNPs: Single nucleotide polymorphisms; TC: Total cholesterol;

TG: Triglycerides; VPA: Vigorous physical activity

\section{Acknowledgments}

Not applicable.

\section{Conflict of interest}

All authors declare: no support from companies for the submitted work; no relationships with companies that might have an interest in the submitted work in the previous 3 years; no spouses, partners, or children have no financial relationships that may be relevant to the submitted work; no nonfinancial interests that may be relevant to the submitted work.

\section{Contributions}

$\mathrm{ZZ}, \mathrm{MG}, \mathrm{RY}, \mathrm{NL}, \mathrm{ZL}, \mathrm{WC}$ and TH designed the research. ZZ and TH had full access to all the data in the study and take responsibility for the integrity of the data and the accuracy of the data analysis. ZZ, MG, RY, NL, ZL, WC and TH wrote the paper and performed the data analysis. All authors contributed to the statistical analysis, critically reviewed the manuscript during the writing process, and approved the final version to be published. $\mathrm{ZZ}$ and TH are the guarantors for the study.

\section{Data availability}

All data used in the present study were obtained from genome wide association study summary statistics which were publicly released by genetic consortia.

\section{Ethical approval and consent to participate}

Contributing studies received ethical approval from their respective institutional review boards. Informed consent was obtained from all participants of contributing studies.

\section{Funding}

The study was supported by grants from the Peking University Start-up Grant (BMU2018YJ002), High-performance Computing Platform of Peking University, and Beijing Technology and Business University Grant: 88442Y0033. The funding organization had no role in the preparation of the manuscript.

\section{Consent for publication}

Not applicable.

\section{Author details}

'Department of Epidemiology \& Biostatistics, School of Public Health, Peking University, 38 Xueyuan Road, Bejing 100191, China. ${ }^{2}$ Institute of Reproductive and Child Health, Peking University/Key Laboratory of Reproductive Health, National Health Commission of the People's Republic of China, Bejing 100191, China. ${ }^{3}$ Department of Statistics and Actuarial Science, The University of Hong Kong, Pok Fu Lam, Hong Kong. ${ }^{4}$ Department of Global Health, School of Public Health, Peking University, Bejing 100191, China. ${ }^{5}$ Key Laboratory of Molecular Cardiovascular Sciences (Peking University), Ministry of Education, Bejing 100191, China.

Received: 21 October 2019 Accepted: 7 April 2020

Published online: 08 May 2020

\section{References}

1. Collins DR, Tompson AC, Onakpoya IJ, Roberts N, Ward AM, Heneghan CJ. Global cardiovascular risk assessment in the primary prevention of cardiovascular disease in adults: systematic review of systematic reviews. BMJ Open. 2017:7:e013650.

2. Lennon RP, Claussen KA, Kuersteiner KA. State of the heart: an overview of the disease burden of cardiovascular disease from an epidemiologic perspective. Primary Care. 2018;45:1-15.

3. Mozaffarian D, Wilson PW, Kannel WB. Beyond established and novel risk factors: lifestyle risk factors for cardiovascular disease. Circulation. 2008;117: 3031-8.

4. Ahmed HM, Blaha MJ, Nasir K, Jones SR, Rivera JJ, Agatston A, Blankstein R, Wong ND, Lakoski S, Budoff MJ, Burke GL, Sibley CT, Ouyang P, Blumenthal RS. Low-risk lifestyle, coronary calcium, cardiovascular events, and mortality: results from MESA. Am J Epidemiol. 2013;178:12-21.

5. Wennman H, Kronholm E, Partonen T, Tolvanen A, Peltonen M, Vasankari T, Borodulin K. Interrelationships of physical activity and sleep with cardiovascular risk factors: a person-oriented approach. Int J Behav Med. 2015;22:735-47.

6. Spencer RM, Heidecker B, Ganz P. Behavioral cardiovascular risk factorseffect of physical activity and cardiorespiratory fitness on cardiovascular outcomes. Circulation J. 2016:80:34-43.

7. Borrell LN. The effects of smoking and physical inactivity on advancing mortality in U.S. adults. Ann Epidemiol. 2014:24:484-7.

8. Dubbert PM, Carithers T, Sumner AE, Barbour KA, Clark BL, Hall JE, Crook ED. Obesity, physical inactivity, and risk for cardiovascular disease. Am J Med Sci. 2002:324:116-26.

9. Wahid A, Manek N, Nichols M, Kelly P, Foster C, Webster P, Kaur A, Friedemann Smith C, Wilkins E, Rayner M, Roberts N, Scarborough P. Quantifying the association between physical activity and cardiovascular disease and diabetes: a systematic review and meta-analysis. J Am Heart Assoc. 2016;5.

10. Arija V, Villalobos F, Pedret R, Vinuesa A, Timon M, Basora T, Aguas D, Basora J. Effectiveness of a physical activity program on cardiovascular disease risk in adult primary health-care users: the "pas-a-pas" community intervention trial. BMC Public Health. 2017:17:576.

11. Healy GN, Winkler EAH, Eakin EG, Owen N, Lamontagne AD, Moodie M, Dunstan DW. A cluster RCT to reduce Workers' sitting time: impact on Cardiometabolic biomarkers. Med Sci Sports Exerc. 2017;49:2032-9.

12. Benn M, Nordestgaard BG. From genome-wide association studies to Mendelian randomization: novel opportunities for understanding cardiovascular disease causality, pathogenesis, prevention, and treatment. Cardiovasc Res. 2018;114:1192-208. 
13. Dairy Intake and Body Composition and Cardiometabolic Traits among Adults: Mendelian Randomization Analysis of 182041 Individuals from 18 Studies. Clin Chem. 2019;65:751-60.

14. Geng T, Smith CE, Li C, Huang T. Childhood BMI and adult type 2 diabetes, coronary artery diseases, chronic kidney disease, and Cardiometabolic traits: a Mendelian randomization analysis. Diabetes Care. 2018;41:1089-96.

15. Ding M, Huang T, Bergholdt HK, Nordestgaard BG, Ellervik C, Qi L. Dairy consumption, systolic blood pressure, and risk of hypertension: Mendelian randomization study. BMJ (Clinical research ed). 2017;356:j1000.

16. Dairy Consumption and Body Mass Index Among Adults. Mendelian randomization analysis of 184802 individuals from 25 studies. Clin Chem. 2018;64:183-91.

17. Zheng J, Baird D, Borges MC, Bowden J, Hemani G, Haycock P, Evans DM, Smith GD. Recent developments in Mendelian randomization studies. Curr Epidemiol Rep. 2017:4:330-45.

18. Choi KW, Chen CY, Stein MB, Klimentidis YC, Wang MJ, Koenen KC, Smoller JW. Assessment of Bidirectional Relationships Between Physical Activity and Depression Among Adults: A 2-Sample Mendelian Randomization Study. JAMA Psychiatry. 2019.

19. Lanier JB, Bury DC, Richardson SW. Diet and physical activity for cardiovascular disease prevention. Am Fam Physician. 2016;93:919-24.

20. Lear SA, Hu W, Rangarajan S, Gasevic D, Leong D, lqbal R, Casanova A, Swaminathan S, Anjana RM, Kumar R, Rosengren A, Wei L, Yang W, Chuangshi W, Huaxing L, Nair S, Diaz R, Swidon H, Gupta R, Mohammadifard N, Lopez-Jaramillo P, Oguz A, Zatonska K, Seron P, Avezum A, Poirier P, Teo K, Yusuf S. The effect of physical activity on mortality and cardiovascular disease in 130000 people from 17 high-income, middleincome, and low-income countries: the PURE study. Lancet (London, England). 2017:390:2643-54.

21. Soares-Miranda L, Siscovick DS, Psaty BM, Longstreth WT Jr, Mozaffarian D. Physical activity and risk of coronary heart disease and stroke in older adults: the cardiovascular health study. Circulation. 2016;133:147-55.

22. Carter S, Hartman Y, Holder S, Thijssen DH, Hopkins ND. Sedentary behavior and cardiovascular disease risk: mediating mechanisms. Exerc Sport Sci Rev. 2017:45:80-6.

23. Despres JP. Physical activity, sedentary Behaviours, and cardiovascular health: when will cardiorespiratory fitness become a vital Sign? Canadian J Cardiol. 2016:32:505-13.

24. Im E, Kim GS. Relationship between sleep duration and Framingham cardiovascular risk score and prevalence of cardiovascular disease in Koreans. Medicine. 2017;96:e7744

25. Cappuccio FP, Cooper D, D'Elia L, Strazzullo P, Miller MA. Sleep duration predicts cardiovascular outcomes: a systematic review and meta-analysis of prospective studies. Eur Heart J. 2011;32:1484-92.

26. Aziz M, Ali SS, Das S, Younus A, Malik R, Latif MA, Humayun C, Anugula D, Abbas G, Salami J, Elizondo JV, Veledar E, Nasir K. Association of Subjective and Objective Sleep Duration as well as sleep quality with non-invasive markers of sub-clinical cardiovascular disease (CVD): a systematic review. J Atheroscler Thromb. 2017;24:208-26.

27. Klimentidis YC, Raichlen DA, Bea J, Garcia DO, Wineinger NE, Mandarino ᄂ, Alexander GE, Chen Z, Going SB. Genome-wide association study of habitual physical activity in over 377,000 UK Biobank participants identifies multiple variants including CADM2 and APOE. Int J Obesity (2005). 2018;42:1161-76.

28. Doherty A, Smith-Byrne K, Ferreira T, Holmes MV, Holmes C, Pulit SL, Lindgren CM. GWAS identifies 14 loci for device-measured physical activity and sleep duration. Nat Commun. 2018;9:5257.

29. Gottlieb DJ, Hek K, Chen TH, Watson NF, Eiriksdottir G, Byrne EM, Cornelis M, Warby SC, Bandinelli S, Cherkas L, Evans DS, Grabe HJ, Lahti J, Li M, Lehtimaki T, Lumley T, Marciante KD, Perusse L, Psaty BM, Robbins J, Tranah GJ, Vink JM, Wilk JB, Stafford JM, Bellis C, Biffar R, Bouchard C, Cade B, Curhan GC, Eriksson JG, Ewert R, Ferrucci L, Fulop T, Gehrman PR, Goodloe R, Harris TB, Heath AC, Hernandez D, Hofman A, Hottenga JJ, Hunter DJ, Jensen MK, Johnson AD, Kahonen M, Kao L, Kraft P, Larkin EK, Lauderdale DS, Luik Al, Medici M, Montgomery GW, Palotie A, Patel SR, Pistis G, Porcu E, Quaye L, Raitakari O, Redline S, Rimm EB, Rotter Jl, Smith AV, Spector TD, Teumer A, Uitterlinden AG, Vohl MC, Widen E, Willemsen G, Young T, Zhang X, Liu Y, Blangero J, Boomsma DI, Gudnason V, Hu F, Mangino M, Martin NG, O'Connor GT, Stone KL, Tanaka T, Viikari J, Gharib SA, Punjabi NM, Raikkonen K, Volzke H, Mignot E, Tiemeier H. Novel loci associated with usual sleep duration: the CHARGE Consortium Genome-Wide Association Study. Mol Psychiatry. 2015;20:1232-9.
30. Nikpay M, Goel A, Won HH, Hall LM, Willenborg C, Kanoni S, Saleheen D, Kyriakou T, Nelson CP, Hopewell JC, Webb TR, Zeng L, Dehghan A, Alver M, Armasu SM, Auro K, Bjonnes A, Chasman DI, Chen S, Ford I, Franceschini N, Gieger C, Grace C, Gustafsson S, Huang J, Hwang SJ, Kim YK, Kleber ME, Lau KW, Lu X, Lu Y, Lyytikainen LP, Mihailov E, Morrison AC, Pervjakova N, Qu L, Rose LM, Salfati E, Saxena R, Scholz M, Smith AV, Tikkanen E, Uitterlinden A, Yang X, Zhang W, Zhao W, de Andrade M, de Vries PS, van Zuydam NR, Anand SS, Bertram L, Beutner F, Dedoussis G, Frossard P, Gauguier D, Goodall AH, Gottesman O, Haber M, Han BG, Huang J, Jalilzadeh S, Kessler T, Konig IR, Lannfelt L, Lieb W, Lind L, Lindgren CM, Lokki ML, Magnusson PK, Mallick NH, Mehra N, Meitinger T, Memon FU, Morris AP, Nieminen MS, Pedersen NL, Peters A, Rallidis LS, Rasheed A, Samuel M, Shah SH, Sinisalo J, Stirrups KE, Trompet S, Wang L, Zaman KS, Ardissino D, Boerwinkle E, Borecki IB, Bottinger EP, Buring JE, Chambers JC, Collins R, Cupples LA, Danesh J, Demuth I, Elosua R, Epstein SE, Esko T, Feitosa MF, Franco OH, Franzosi MG, Granger CB, Gu D, Gudnason V, Hall AS, Hamsten A, Harris TB, Hazen SL, Hengstenberg C, Hofman A, Ingelsson E, Iribarren C, Jukema JW, Karhunen PJ, Kim BJ, Kooner JS, Kullo IJ, Lehtimaki T, RJF L, Melander O, Metspalu A, Marz W, Palmer CN, Perola M, Quertermous T, Rader DJ, Ridker PM, Ripatti S, Roberts R, Salomaa V, Sanghera DK, Schwartz SM, Seedorf U, Stewart AF, Stott DJ, Thiery J, Zalloua PA, O'Donnell CJ, Reilly MP, Assimes TL, Thompson JR, Erdmann J, Clarke R, Watkins H, Kathiresan S, McPherson R, Deloukas P, Schunkert H, Samani NJ, Farrall M. A comprehensive 1,000 Genomes-based genome-wide association meta-analysis of coronary artery disease. Nat Genet. 2015;47:1121-30.

31. Loci associated with ischaemic stroke and its subtypes (SiGN): a genomewide association study. Lancet Neurol. 2016;15:174-84.

32. Willer CJ, Schmidt EM, Sengupta S, Peloso GM, Gustafsson S, Kanoni S, Ganna A, Chen J, Buchkovich ML, Mora S, Beckmann JS, Bragg-Gresham JL, Chang HY, Demirkan A, Den Hertog HM, Do R, Donnelly LA, Ehret GB, Esko T, Feitosa MF, Ferreira T, Fischer K, Fontanillas P, Fraser RM, Freitag DF, Gurdasani D, Heikkila K, Hypponen E, Isaacs A, Jackson AU, Johansson A, Johnson T, Kaakinen M, Kettunen J, Kleber ME, Li X, Luan J, Lyytikainen LP, Magnusson PKE, Mangino M, Mihailov E, Montasser ME, Muller-Nurasyid M, Nolte IM, O'Connell JR, Palmer CD, Perola M, Petersen AK, Sanna S, Saxena R, Service SK, Shah S, Shungin D, Sidore C, Song C, Strawbridge RJ, Surakka I, Tanaka T, Teslovich TM, Thorleifsson G, Van den Herik EG, Voight BF, Volcik KA, Waite LL, Wong A, Wu Y, Zhang W, Absher D, Asiki G, Barroso I, Been LF, Bolton JL, Bonnycastle LL, Brambilla P, Burnett MS, Cesana G, Dimitriou M, Doney ASF, Doring A, Elliott P, Epstein SE, Ingi Eyjolfsson G, Gigante B, Goodarzi MO, Grallert H, Gravito ML, Groves CJ, Hallmans G, Hartikainen AL, Hayward C, Hernandez D, Hicks AA, Holm H, Hung YJ, Illig T, Jones MR, Kaleebu P, Kastelein JJP, Khaw KT, Kim E, Klopp N, Komulainen P, Kumari M, Langenberg C, Lehtimaki T, Lin SY, Lindstrom J, Loos RJF, Mach F, McArdle WL, Meisinger C, Mitchell BD, Muller G, Nagaraja R, Narisu N, Nieminen TVM, Nsubuga RN, Olafsson I, Ong KK, Palotie A, Papamarkou T, Pomilla C, Pouta A, Rader DJ, Reilly MP, Ridker PM, Rivadeneira F, Rudan I, Ruokonen A, Samani N, Scharnagl H, Seeley J, Silander K, Stancakova A, Stirrups K, Swift AJ, Tiret L, Uitterlinden AG, van Pelt LJ, Vedantam S, Wainwright N, Wijmenga C, Wild SH, Willemsen G, Wilsgaard T, Wilson JF, Young EH, Zhao JH, Adair LS, Arveiler D, Assimes TL, Bandinelli S, Bennett F, Bochud M, Boehm BO, Boomsma DI, Borecki IB, Bornstein SR, Bovet P, Burnier M, Campbell H, Chakravarti A, Chambers JC, Chen YI, Collins FS, Cooper RS, Danesh J, Dedoussis G, de Faire U, Feranil AB, Ferrieres J, Ferrucci L, Freimer NB, Gieger C, Groop LC, Gudnason V, Gyllensten U, Hamsten A, Harris TB, Hingorani A, Hirschhorn JN, Hofman A, Hovingh GK, Hsiung CA, Humphries SE, Hunt SC, Hveem K, Iribarren C, Jarvelin MR, Jula A, Kahonen M, Kaprio J, Kesaniemi A, Kivimaki M, Kooner JS, Koudstaal PJ, Krauss RM, Kuh D, Kuusisto J, Kyvik KO, Laakso M, Lakka TA, Lind L, Lindgren CM, Martin NG, Marz W, McCarthy MI, McKenzie CA, Meneton P, Metspalu A, Moilanen L, Morris AD, Munroe PB, Njolstad I, Pedersen NL, Power C, Pramstaller PP, Price JF, Psaty BM, Quertermous T, Rauramaa R, Saleheen D, Salomaa V, Sanghera DK, Saramies J, Schwarz PEH, Sheu WH, Shuldiner AR, Siegbahn A, Spector TD, Stefansson K, Strachan DP, Tayo BO, Tremoli E, Tuomilehto J, Uusitupa M, van Duijn CM, Vollenweider P, Wallentin L, Wareham NJ, Whitfield JB, Wolffenbuttel BHR, Ordovas JM, Boerwinkle E, Palmer CNA, Thorsteinsdottir U, Chasman DI, Rotter II, Franks PW, Ripatti S, Cupples LA, Sandhu MS, Rich SS, Boehnke M, Deloukas $P$, Kathiresan S, Mohlke KL, Ingelsson E, Abecasis GR. Discovery and refinement of loci associated with lipid levels. Nat Genet 2013; 45:1274-1283.

33. Bennett DA, Du H, Clarke R, Guo Y, Yang L, Bian Z, Chen Y, Millwood I, Yu C, He P, Zheng $X$, Collins R, Chen J, Peto R, Li L, Chen Z. Association of Physical Activity with Risk of major cardiovascular diseases in Chinese men and women. JAMA Cardiol. 2017;2:1349-58. 
34. Boss HM, Kappelle LJ, Van Der Graaf Y, Kooistra M, Visseren FL, Geerlings MI. Physical activity and vascular events and mortality in patients with vascular disease. Med Sci Sports Exerc. 2015;47:2359-65.

35. Pozuelo-Carrascosa DP, Garcia-Hermoso A, Alvarez-Bueno C, Sanchez-Lopez M, Martinez-Vizcaino V. Effectiveness of school-based physical activity programmes on cardiorespiratory fitness in children: a meta-analysis of randomised controlled trials. Br J Sports Med. 2018;52:1234-40.

36. Winzer EB, Woitek F, Linke A. Physical activity in the prevention and treatment of coronary artery disease. J Am Heart Assoc. 2018;7:e007725.

37. Koolhaas CM, Dhana K, Golubic R, Schoufour JD, Hofman A, van Rooij FJ, Franco $\mathrm{OH}$. Physical activity types and coronary heart disease risk in middleaged and elderly persons: the Rotterdam study. Am J Epidemiol. 2016;183: 729-38.

38. Lakka TA, Venalainen JM, Rauramaa R, Salonen R, Tuomilehto J, Salonen JT. Relation of leisure-time physical activity and cardiorespiratory fitness to the risk of acute myocardial infarction. N Engl J Med. 1994;330:1549-54.

39. Zhao S, Zhang Z, Long Q, Ma Y, Lian X, Yang Y, Gao W, Chen Z, Wang L. Association between time of day of sports-related physical activity and the onset of acute myocardial infarction in a Chinese population. PLoS One. 2016;11:e0146472.

40. Yu L, Liang Q, Zhou W, Huang X, Hu L, You C, Li J, Wu Y, Li P, Wu Q, Wang $Z$, Gao R, Bao H, Cheng X. Association between physical activity and stroke in a middle-aged and elderly Chinese population. Medicine. 2018;97:e13568.

41. Jeong HG, Kim DY, Kang DW, Kim BJ, Kim CK, Kim Y, Yang W, Park ES, Lee SH. Physical activity frequency and the risk of stroke: a Nationwide cohort study in Korea. J Am Heart Assoc. 2017;6.

42. Kubota Y, Iso H, Yamagishi K, Sawada N, Tsugane S. Daily Total physical activity and incident stroke: the Japan public health center-based prospective study. Stroke. 2017;48:1730-6.

43. Omar A, Husain MN, Jamil AT, Nor NSM, Ambak R, Fazliana M, Zamri NLA, Aris T. Effect of physical activity on fasting blood glucose and lipid profile among low income housewives in the MyBFF@home study. BMC Womens Health. 2018;18:103.

44. Eftekhari E, Zafari A, Gholami M. Physical activity, lipid profiles and leptin. J Sports Med Phys Fitness. 2016;56:465-9.

45. Grandner MA, Chakravorty S, Perlis ML, Oliver L, Gurubhagavatula I. Habitual sleep duration associated with self-reported and objectively determined cardiometabolic risk factors. Sleep Med. 2014;15:42-50.

46. Hoevenaar-Blom MP, Spijkerman AM, Kromhout D, Verschuren WM. Sufficient sleep duration contributes to lower cardiovascular disease risk in addition to four traditional lifestyle factors: the MORGEN study. Eur J Prev Cardiol. 2014;21:1367-75.

47. Orkaby AR, Forman DE. Physical activity and CVD in older adults: an expert's perspective. Expert Rev Cardiovasc Ther. 2018;16:1-10.

48. Fiuza-Luces C, Santos-Lozano A, Joyner M, Carrera-Bastos P, Picazo O, Zugaza JL, Izquierdo M, Ruilope LM, Lucia A. Exercise benefits in cardiovascular disease: beyond attenuation of traditional risk factors. Nat Rev Cardiol. 2018:15:731-43.

49. Au Yeung SL, Jiang C, Cheng KK, Cowling BJ, Liu B, Zhang W, Lam TH, Leung GM, Schooling CM. Moderate alcohol use and cardiovascular disease from Mendelian randomization. PLoS One. 2013;8:e68054.

\section{Publisher's Note}

Springer Nature remains neutral with regard to jurisdictional claims in published maps and institutional affiliations.

\section{Ready to submit your research? Choose BMC and benefit from}

- fast, convenient online submission

- thorough peer review by experienced researchers in your field

- rapid publication on acceptance

- support for research data, including large and complex data types

- gold Open Access which fosters wider collaboration and increased citations

- maximum visibility for your research: over $100 \mathrm{M}$ website views per year

At BMC, research is always in progress.

Learn more biomedcentral.com/submissions 